University of the Pacific

Scholarly Commons

All Faculty Articles - School of Engineering and Computer Science

All Faculty Scholarship

4-1-2018

\title{
Fluids Demonstrations: Trailing Vortices, Plateau Border, Angle of Repose, and Flow Instability
}

\section{Said Shakerin}

University of the Pacific, sshakerin@pacific.edu

Follow this and additional works at: https://scholarlycommons.pacific.edu/soecs-facarticles

Part of the Mechanical Engineering Commons

\section{Recommended Citation}

Shakerin, S. (2018). Fluids Demonstrations: Trailing Vortices, Plateau Border, Angle of Repose, and Flow Instability. Physics Teacher, 56(4), 248-252. DOI: 10.1119/1.5028244

https://scholarlycommons.pacific.edu/soecs-facarticles/91

This Article is brought to you for free and open access by the All Faculty Scholarship at Scholarly Commons. It has been accepted for inclusion in All Faculty Articles - School of Engineering and Computer Science by an authorized administrator of Scholarly Commons. For more information, please contact mgibney@pacific.edu. 


\section{$\int_{0}^{\frac{c}{0}}$ \\ Fluids Demonstrations: Trailing Vortices, Plateau Border, Angle of Repose, and Flow Instability}

Cite as: Phys. Teach. 56, 248 (2018); https://doi.org/10.1119/1.5028244

Published Online: 16 March 2018

\section{Said Shakerin}

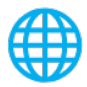

\section{ARTICLES YOU MAY BE INTERESTED IN}

Serious Fun: Using Toys to Demonstrate Fluid Mechanics Principles

The Physics Teacher 52, 332 (2014); https://doi.org/10.1119/1.4893085

Fluids Demonstrations II: Bubbles in Mondrian Painting, Eruption-Like Flow, Rotational Instability, and Wake Vortices

The Physics Teacher 57, 600 (2019); https://doi.org/10.1119/1.5135786

Flawed Applications of Bernoulli's Principle

The Physics Teacher 56, 235 (2018); https://doi.org/10.1119/1.5028240

\section{AAPT}

Advance your teaching and career as a member of AAPT 


\section{Fluids Demonstrations: Trailing Vortices, Plateau Border, Angle of Repose, and Flow Instability}

Said Shakerin, University of the Pacific, Stockton, CA

$\mathrm{D}$ emonstrations of physics phenomena via relatively simple devices and toys have been around for a long time. Because of the pedagogical value of demonstrations, this journal and other periodicals have published papers on the subject of classroom demonstrations including those related to fluid mechanics. ${ }^{1-6}$ Four new, low-cost apparatuses that demonstrate a variety of fluid mechanics phenomena are presented in this paper. The apparatuses are self-contained,

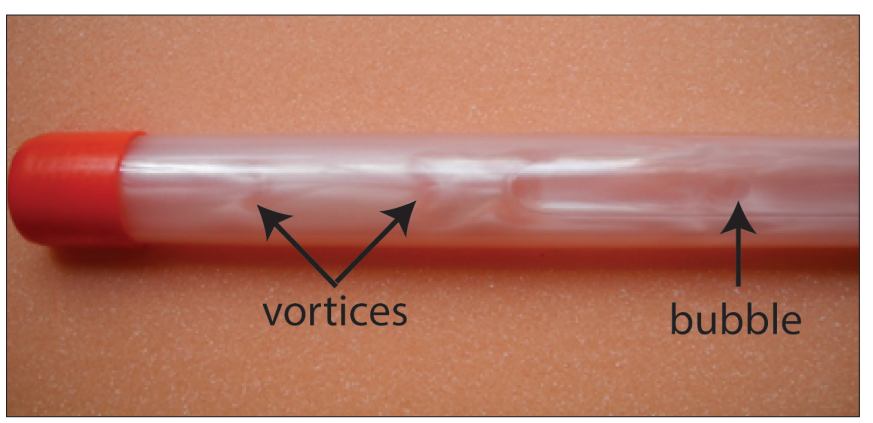

Fig. 1. Trailing vortices shown behind the air bubble moving from left to right. The tube is 12 in long with a nominal diameter of 1 in. (Inches are used throughout the paper because all parts were purchased in the United States, where the English system is commercially used to specify parts.)

instantly set up, require no electric power for operation, and are maintenance free. They can be used as demonstration tools to enhance classroom lectures and outreach activities. Alternatively, these apparatuses can be assigned as projects for students to construct and test. Further involvement, from an aesthetic point of view, might be to construct variations of them as decorative objects by collaborating with students/ teachers in visual arts. Features of the apparatuses are presented first, followed by notes on fabrication to enable interested readers to replicate them.

\section{Features of apparatuses}

\section{Trailing vortices}

Trailing vortices that form behind an object moving in a fluid are demonstrated with this sealed tube, which contains rheoscopic fluid and an air bubble that serves as the object, shown in Fig. 1 . These vortices are an important consideration in determining drag on objects moving through fluids. Background information about trailing vortices can usually be found in fluid mechanics textbooks that include a chapter on external flows. ${ }^{7}$ The rheoscopic fluid, composed of water and pearllike crystals (additive), is sensitive to local shear, thereby enabling flow visualization. The tube is held in a groove on a foam base that is housed in a box. The bubble is large enough to be clearly seen, and is set in motion by pressing down on one end of the tube, slightly tilting it. Visible trailing vortices are formed as the bubble moves through the tube.

It is easy to operate the tube. If the tube has been idle for a while, it should be first shaken to remix the content as settling of the additive does take place in rheoscopic fluid. After a few seconds and when large eddies are settled, the tube is placed back into the foam and ready for demonstration. With your thumb gently press down on one end of the tube and watch the trailing vortices as the bubble moves through the tube. If the bubble is made to move very slowly, by applying light pressure to the tube, no trailing vortices will be observed. However, as the bubble is made to move a little faster, trailing vortices are formed and clearly seen. By controlling the applied pressure (in separate attempts), the number of trailing vortices can be changed from none to several and onto fully turbulent flow. A discussion of Reynolds number, ${ }^{7}$ which is a dimensionless ratio of inertial to viscous forces, may follow this demonstration depending on the level of presentation and audience.
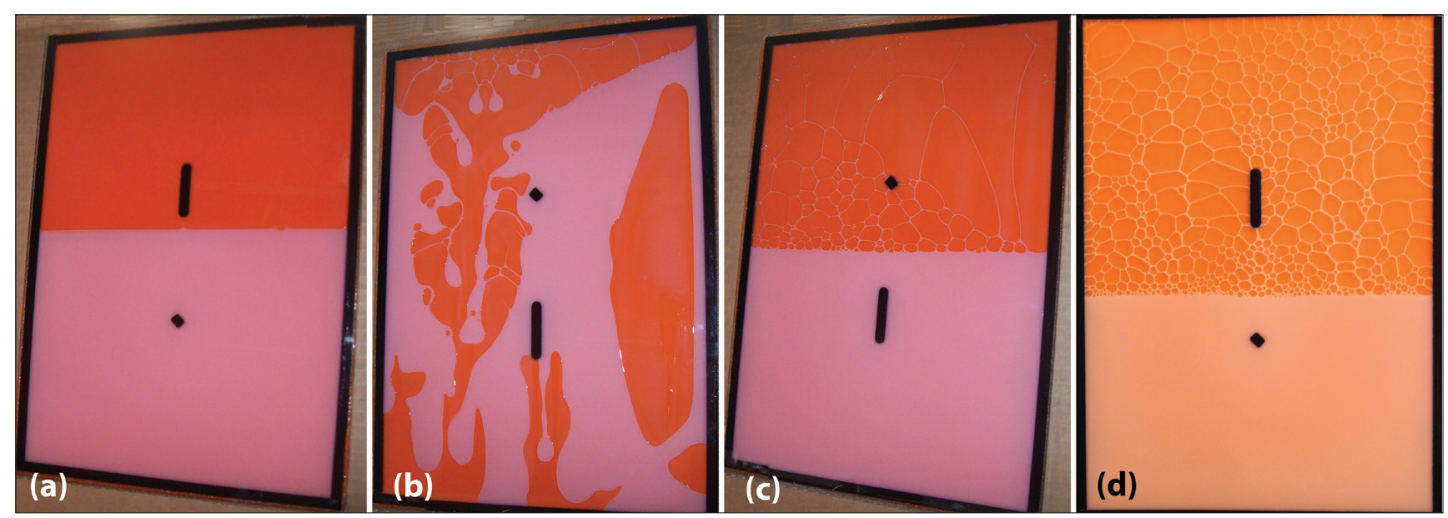

Fig. 2. (a) The soap is at the bottom of enclosure while idle. The small black square and bar are acrylic spacers, $1 / 4$ in wide, in the enclosure; they also serve as orientation markers. (b) After the enclosure is turned upside down, the interaction between downward flowing soap and creeping up air creates visually engaging patterns. (c)-(d) Plateau borders occupy the space above the soap. Image (d) was taken after several more turns. The enclosure overall size: 12 x 8.5 in. 


\section{Plateau border}

Soap films obey specific arrangements called Plateau laws, the third law of which is demonstrated with this vertically oriented thin and sealed enclosure, containing liquid soap and air, see Fig. 2. The third law states that soap films meet in threes along an edge called a Plateau border. Scientific information about the arrangements in soap films can be found in the popular press in addition to journals. ${ }^{8}$ For brevity and from here on, thin enclosure refers to an enclosure with $1 / 16$ in of spacing between its front and back surfaces. While idle, the soap is at rest at the bottom and air is at the top of the enclosure, Fig. 2(a). When the enclosure is turned upside down, the soap flows down due to the gravity and air must flow up to make room, creating random patterns of soap bubble clusters creeping up through the soap, see Fig. 2(b). Since the enclosure is thin, soap bubbles are flattened, formed in one layer, and therefore clearly seen. Plateau borders can be observed, as shown in Figs. 2(c)-(d), once the overall flow stops and most of the soap has been drained from the soap films. (Two flow instabilities are also observable with this enclosure, but that topic is covered in another apparatus below.)

Based on the author's experience, there is a tendency for the soap in the enclosure to turn into gel after about 18 months. As a result the Plateau border demonstration may not work as described after that period of time.

As a companion, an annulus enclosure is also presented for the same demonstration but in a different geometry. The annulus is made of PVC pipe as an inner cylinder (previously sealed at both ends by gluing acrylic disks) and a plastic storage tube as an outer cylinder. Plastic caps, sold with the storage tube, seal the annulus enclosure. Sample images are shown in Fig. 3.

\section{Angle of repose}

Angle of repose-an important characteristic of granular flow $^{9}$-is demonstrated with this vertically oriented thin enclosure containing dry sand and air. The enclosure is shown in Fig. 4(a). Multiple rod segments or partitions divide the enclosure into several rows. When the enclosure is turned upside down, the sand flows down and through the gaps between the partitions. Because the partitions are staggered, piles of sand are formed on each of them, clearly demonstrating the angle of repose. Note that the angle seen in Fig. 4(b) is more than the angle reported in the case of free flowing dry sand, which is approximately $35^{\circ}$. This difference is due to the friction with enclosure walls. Turning the enclosure to other angles results in different mounds, with an example shown in Fig. 4(c).

\section{Flow instability}

Flow instability, ${ }^{10}$ an advanced topic in fluid mechanics but observable in every day experiences, is demonstrated with this vertically oriented thin and sealed enclosure containing dyed glycerin and air, shown in Fig. 5(a). Glycerin can be dyed by adding a small amount of icing color if desired. When idle, glycerin, the heavier fluid, is at rest at the bottom
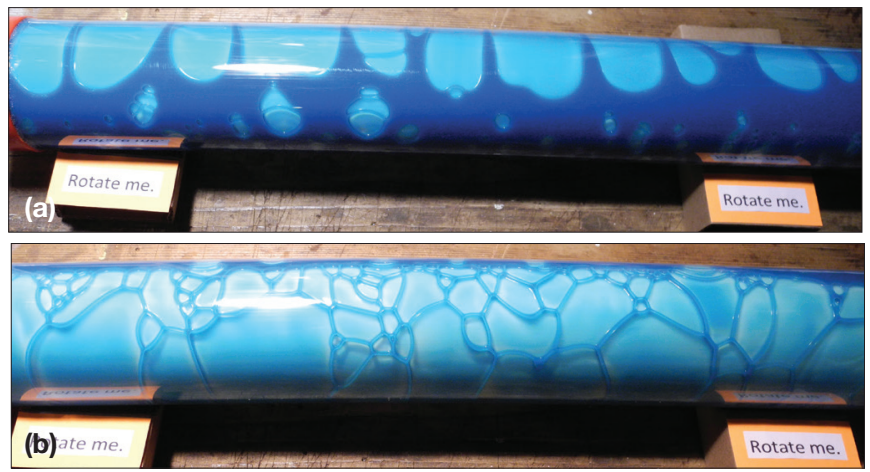

Fig. 3. (a) Interaction between soap and air bubbles in annulus enclosure. (b) Plateau borders seen in annulus enclosure. Blue food color was added to the white soap. The overall length: 24 in, nominal diameters are 3 in, providing an annulus gap of 1/16 in.

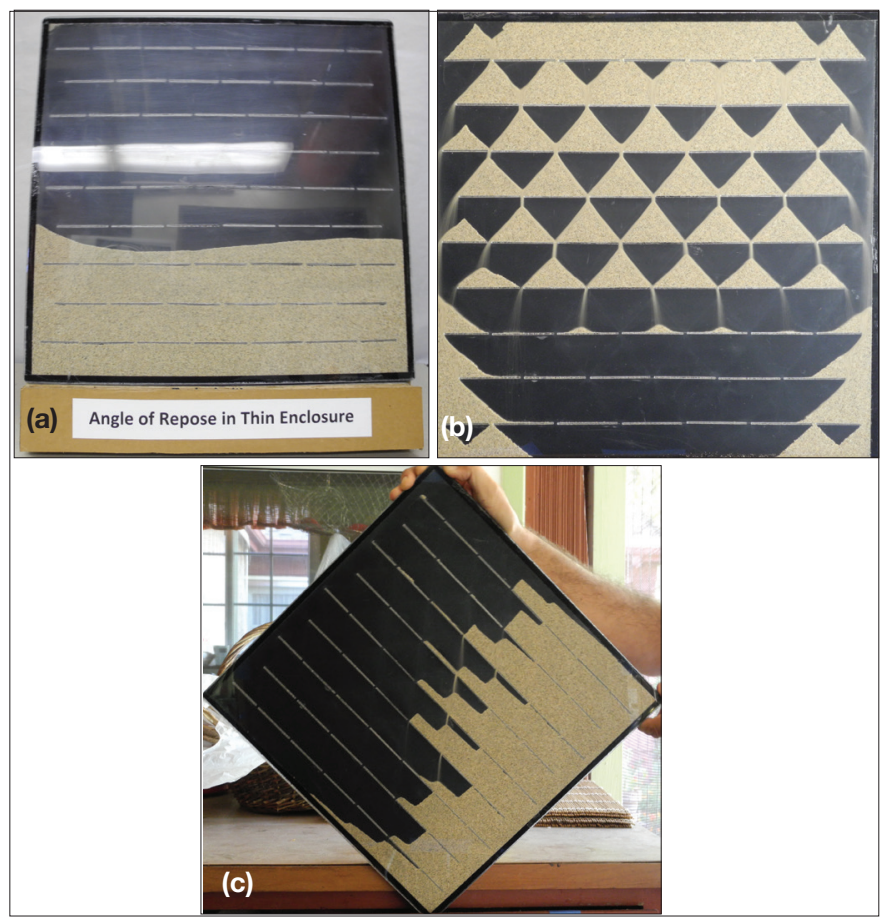

Fig. 4. (a) Enclosure on its cardboard stand shown with sand at the bottom (this can be achieved by rocking the enclosure sideto-side until all sand is collected at the bottom). (b) After turning the enclosure $180^{\circ}$, sand flows through partition gaps and forms mounds on partitions, exhibiting the angle of repose. (c) Enclosure turned to a different angle. Image (b) appeared in the "Visual Physics" column of The Physics Teacher, March 2016 issue.

and air is at the top of the enclosure. This stable condition can easily be changed to an unstable condition by turning the enclosure upside down. Now the glycerin is at the top and gravity causes it to flow down while air has to flow up, creating a dynamic interaction between the two fluids as they exchange their places. This unstable situation gives rise to an undulation at the interface of the two fluids and is known as Rayleigh-Taylor instability; see Figs. 5(b) and (c).

Another fluid instability can be also demonstrated with this enclosure. When the two sides of the enclosure are pressed together near the fluids' interface, the fluids are forced out from the area. Upon releasing the pressure, air, 


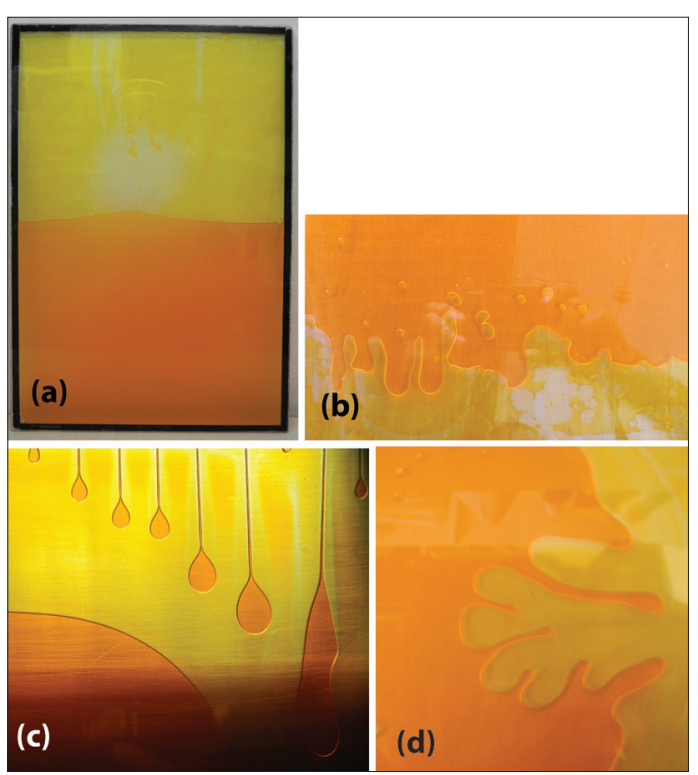

Fig 5. (a) Thin enclosure containing dyed glycerin and air. (b) Undulation at the fluids' interface while the enclosure was turned upside down. (c) Droplets break away from the top edge near the end of a demonstration, also demonstrating Rayleigh-Taylor instability. (d) Saffman-Taylor instability while the enclosure is horizontal. A cropped version of image (c) appeared in the "Visual Physics" column of The Physics Teacher, January and February 2016 issues.
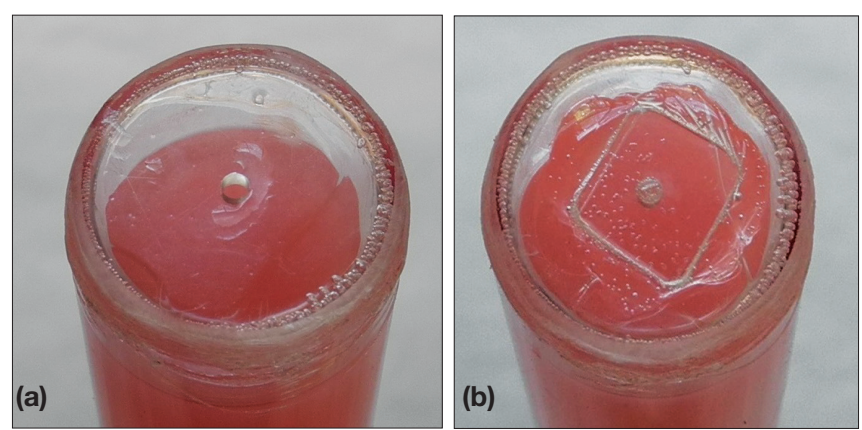

Fig. 6. (a) Tube's end with filling hole and air space. (b) Square piece covers and seals the hole.

which is the less viscous fluid, rushes in and gives rise to a fingering pattern named Saffman-Taylor instability; see Fig. $5(d)$.

\section{Notes on fabrication}

A list and a photograph of materials and supplies that are needed to fabricate the apparatuses are presented in Appendix A. It is assumed the person making them is familiar with techniques such as cutting, sanding, drilling, etc., and can work safely with hand and power tools (e.g., electric drill and table saw). Since three of the apparatuses contain liquids, it is essential to make leak proof joints between acrylic parts. Online resources to help with acrylic fabrication techniques are available. ${ }^{11}$ Step-by-step instructions are presented below for the trailing vortices apparatus and a simple thin enclosure that can be used for either the Plateau border or instability apparatuses.

\section{Fabrication instruction for trailing vortices apparatus}

The trailing vortices apparatus is the simplest of the four apparatuses to make because it is simply a sealed acrylic tube. From a thin sheet of acrylic ( $\leq 1 / 16$-in thick) cut two squares, a little wider than the tube's diameter. Using syrup-like acrylic glue, attach one square to an end of the tube. Drill a small hole at the center of the second square and glue it onto the other end of the tube. The hole serves two purposes. It allows extra vapor to escape without creating gaps in the wet glue as it dries. It also allows insertion of a hypodermic needle to fill the tube with rhescopic fluid. Let the glue completely dry. Trim extra acrylic and sand the edges for a smooth finish. Using a dispenser fitted with a hypodermic needle, fill the tube with rhescopic fluid but leave about $1 / 2$ in of air space as shown in Fig. 6(a). Glue a small square piece of acrylic to cover and seal the hole as shown in Fig. 6(b).

Cover the tube's ends with plastic caps and apply syruplike glue to seal the tube assembly. Rheoscopic fluid is available for purchase from an educational supplier, and it can easily be dyed with food color. Use a craft knife to cut the groove in the foam. A simple box made of scrap cardboard securely holds the foam.

\section{Fabrication instruction for simple thin enclosure}

The word "simple" here refers to an enclosure without any partition. It is highly recommended that one makes a simple enclosure before fabricating an enclosure with partitions such as that needed for the angle of repose demonstration. 


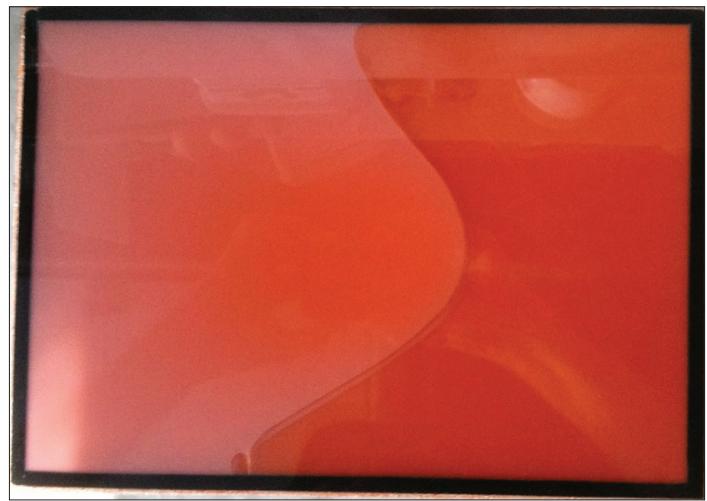

Fig. 8. A simple thin enclosure that contains white liquid dish soap and air. The enclosure is shown flat on a horizontal plane.

The enclosure is made entirely of acrylic sheet stock. The front and back are usually $1 / 8$-in thick and cut to desired size. (Thicker sheets such as 1/4-in thick should be used for larger enclosures to prevent bowing in the middle of the enclosure.) The front is clear and the colored back can be used for better contrast. Four $1 / 4$-in wide strips cut from $1 / 16$-in thick acrylic sheet serve as edge strips around the enclosure. A small portion of one of the strips is cut, but saved, for an opening to fill the liquid with the aid of a dispenser bottle with hypodermic needle. All parts, except the small cutout, are glued together with acrylic cement. It is highly recommended to inset each edge strip about $1 / 16$ in to create a groove around the enclosure. Also, to prevent scratching the acrylic surfaces, their protective covers are not peeled off until the acrylic cement is to be applied to a given surface. Figure 7 shows the above steps.

The liquid is then injected into the opening with a hypodermic needle. The saved cutout piece is placed and glued in the opening. Finally, the syrup-like acrylic glue is applied in the groove and around the edges to further seal and reinforce all the joints. The final result is shown in Fig. 8.

It should be noted that in larger enclosures made of $1 / 8$-in thick stock there is a tendency for the front and back surfaces to bow inward. This can be prevented by incorporating small spacer(s), similar to what is shown in Fig. 1, in the enclosure.

Finally, for the angle of repose apparatus, where there are many small partitions in the enclosure, special care is required to glue the partitions in place. Further fabrication details with respect to partitions will be provided upon request (please send email to the author). Practice on scraps before final fabrication. Also, the edge opening should be at least 4 in long to allow sufficient opening to pour the sand. The sand is poured into the enclosure via a trough made of regular paper with a valley fold that is inserted in the opening. The sand is poured in small amounts and very slowly to prevent jamming.

\section{Summary}

All apparatuses in this paper can be fabricated with a budget of less than $\$ 200$ (supply and materials only). They were exhibited at the Apparatus Competition during the 2016 AAPT

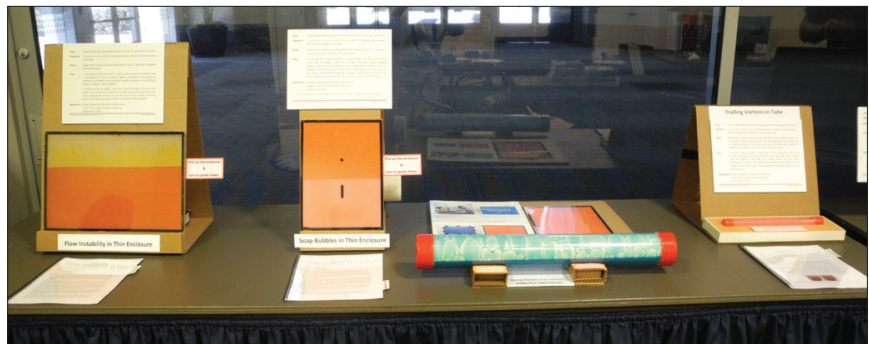

Fig. 9. Display of the apparatuses at the 2016 Apparatus Competition (angle of repose not shown).

National Meeting in Sacramento as shown in Fig. 9. Due to the simplicity of design the apparatuses can be set up instantly and used repeatedly over a long period of time. Furthermore, there is no clean-up. In the author's experience, these science-based demonstrations with engaging and surprising visual elements are attractive to children, e.g., see Fig. 10.

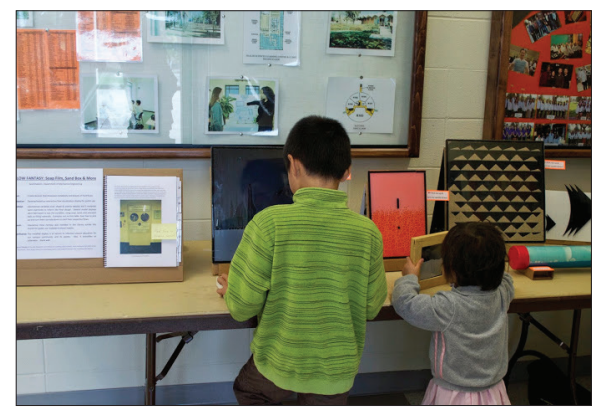

Fig. 10. Children playing with the apparatuses during a poster session open to the public at our university. The child in the green shirt is interacting with the trailing vortices demo to see if he could get the laminar vs. turbulent flow conditions.

\section{Acknowledgments}

The author would like to especially thank David Maiullo for his sponsorship, which enabled the author to participate at the 2016 AAPT Apparatus Competition, and encouragement to write this article. Jonathan Sweet and Mahnaz Saremi assisted in taking photographs shown in Figs. 2, 4, and 5. The apparatuses presented in this paper were developed as part of a project funded by the Faculty Research Committee of the University of the Pacific. One anonymous reviewer provided helpful comments that greatly improved the quality of the paper.

\section{References}

1. R. E. Berg, "Resource Letter PhD-2: Physics demonstrations," Am. J. Phys. 80, 181-191 (March 2012).

2. Physics on Stage 2 \& 3: Demonstrations and Teaching Ideas, selected by the Irish teams (2010). Available at http://www. iopireland.org/education/resources/pos/file_49920.pdf.

3. L. A. Garrison and T. J. Garrison, "A demo every day: Bringing fluid mechanics to life," Proceedings of the 122nd ASEE Annual Conference \& Exposition (Seattle, WA, 2015), Paper ID \# 11842. Available at https://www.asee.org/public/conferences/56/ papers/11842/download. 
4. S. Shakerin, "Vortex apparatus and demonstrations," Phys. Teach. 48, 316-318 (May 2010).

5. C. M. Saviz and S. Shakerin, "Serious fun: Using toys to demonstrate fluid mechanics principles," Phys. Teach. 52, 332-325 (Sept. 2014).

6. J. Bisquert, P. Ramirez, A. J. Barbero, and S. Mafe, "A classroom demonstration on air drag force," Eur. J. Phys. 12, 249-252 (1991).

7. A. J. Smits, A Physical Introduction to Fluid Mechanics, 2nd ed. (Self-published, Princeton, 2017), pp. 181-187. Available at http://www.efluids.com/efluids/books/Smits_text_part1.pdf.

8. F. J. Almgren and J. E. Taylor, "The geometry of soap films and soap bubbles," Sci. Am. 235, 82-93 (July 1976).

9. J. Kakalios, "Resource Letter GP-1: Granular physics or nonlinear dynamics in a sandbox," Am. J. Phys. 73, 8-22 (Jan. 2005).

10. R. F. Benjamin, "Rayleigh-Taylor instability - Fascinating gateway to the study of fluid dynamics," Phys. Teach. 37, 332-337 (Sept. 1999). For Saffman-Taylor instability, visit http://www. flowvis.org/category/flow-categories/saffman-taylor-instability/. For general discussion on flow instabilities, type "Flow Instabilities" in your search engine to download an eight-page pdf document titled "Flow Instabilities - MIT," http://web.mit. $\mathrm{edu} / \mathrm{hml} / \mathrm{ncfmf} / 15 \mathrm{FI}$.pdf. There is also available a 28-minute video in conjunction with the document at https://www. youtube.com/watch? $\mathrm{v}=$ yutbmcO5g2o.

11. For example, view instructional videos on cutting and gluing acrylic at https://www.tapplastics.com/product_info/videos. Also, type "Acrylic Sheet Fabrication Manual" in your search engine to read/download a 36-page manual with the same title.

\section{Appendix A - Materials/Supplies List}

(Excluding general items such as electric drill, scrap cardboard, etc.).

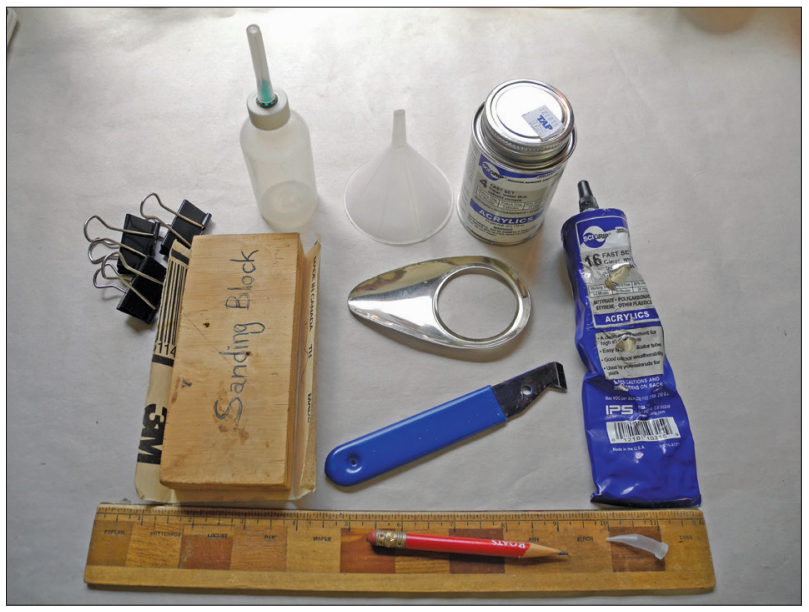

Fig. A1. Tools and supplies (from top right and CW): acrylic cement can, syrup-like acrylic glue tube, ruler, micro-tip (for glue tube), pencil, sanding block and sandpaper (to smooth the edges), spring clips, plastic dispensing bottle with hypodermic blunt tip, funnel and trough (for pouring acrylic cement into dispensing bottle), and (center) acrylic knife (to score and cut sheets of acrylic, up to $3 / 16$ in). Need two hypodermic tips: a fine gauge for acrylic cement and a normal gauge for the enclosure's content (e.g., soap).

\begin{tabular}{|c|c|c|c|c|}
\hline Item & Quantity & Size & Source & Price, \$ \\
\hline $\begin{array}{l}\text { acrylic tube } \\
\text { with } 2 \text { caps }\end{array}$ & 1 & $12 \times 1$ in $0 D$ & $\begin{array}{l}\text { plastic } \\
\text { supplier }^{1}\end{array}$ & $<10.00$ \\
\hline $\begin{array}{l}\text { acrylic sheet, } \\
1 / 8 \text { in thick }\end{array}$ & 6 & $12 \times 12$ in & $\begin{array}{l}\text { plastic } \\
\text { supplier }^{1}\end{array}$ & $\begin{array}{l}6 @ \\
10.00 \\
\text { each }\end{array}$ \\
\hline $\begin{array}{l}\text { acrylic sheet, } \\
1 / 16 \text { in thick }\end{array}$ & 1 & $12 \times 6$ in & $\begin{array}{l}\text { plastic } \\
\text { supplier }\end{array}$ & 5.00 \\
\hline $\begin{array}{l}\text { acrylic rod, } \\
1 / 16 \text {-in } \\
\text { diameter }\end{array}$ & 1 & $6 \mathrm{ft}$ long & $\begin{array}{l}\text { plastic } \\
\text { supplier }\end{array}$ & $<1.00$ \\
\hline acrylic knife & 1 & & $\begin{array}{l}\text { plastic } \\
\text { supplier }\end{array}$ & 2.35 \\
\hline acrylic cement & 1 & 4-0z can & $\begin{array}{l}\text { plastic } \\
\text { supplier }\end{array}$ & 7.25 \\
\hline $\begin{array}{l}\text { applicator } \\
\text { bottle }\end{array}$ & 1 & 2-oz bottle & $\begin{array}{l}\text { plastic } \\
\text { supplier }\end{array}$ & 3.50 \\
\hline funnel \& trough & 1 of each & & $\begin{array}{l}\text { plastic } \\
\text { supplier }\end{array}$ & $<5.00$ \\
\hline $\begin{array}{l}\text { syrup-like } \\
\text { acrylic glue }\end{array}$ & 2 & 5-0z tube & $\begin{array}{l}\text { plastic } \\
\text { supplier }\end{array}$ & $\begin{array}{l}2 @ 9.25 \\
\text { each }\end{array}$ \\
\hline $\begin{array}{l}\text { micro tip (for } \\
\text { glue tube) }\end{array}$ & 1 & & $\begin{array}{l}\text { plastic } \\
\text { supplier }\end{array}$ & 1.35 \\
\hline $\begin{array}{l}\text { rheoscopic } \\
\text { fluid }\end{array}$ & 1 & $1-L$ bottle & $\begin{array}{l}\text { educational } \\
\text { supplier }^{3}\end{array}$ & 16.95 \\
\hline $\begin{array}{l}\text { packaging } \\
\text { foam }\end{array}$ & 1 & $\sim 1 \mathrm{ft}^{2}$ & office supply & $<10.00$ \\
\hline sand & 1 & small bag & home center & $<5.00$ \\
\hline $\begin{array}{l}\text { liquid dish } \\
\text { washing soap }\end{array}$ & 1 & small bottle & $\begin{array}{l}\text { grocery } \\
\text { store }\end{array}$ & $<5.00$ \\
\hline food color & 1 & small bottle & $\begin{array}{l}\text { grocery } \\
\text { store }\end{array}$ & $<3.00$ \\
\hline glycerin & 1 & small bottle & drug store & $<7.00$ \\
\hline icing dye & 1 & 1-oz can & $\begin{array}{l}\text { art supply } \\
\text { store }^{4}\end{array}$ & 2.29 \\
\hline Total & & & & 163.14 \\
\hline
\end{tabular}

1. An example of plastic supplier is found at http://www.tapplastics.com.

2. The edge strips are cut from this item. The supplier may cut the $1 / 4$-in wide strips upon request. Otherwise, a table saw with fine tooth blade is needed to cut the strips.

3. An example of educational supplier is found at http://www.enasco. com. The 1-L bottle provides much more fluid than needed for the demonstration presented in the paper. Use extras for other flow visualization purposes.

4. An example of art supply store is found at http://www.michaels.com.

Said Shakerin is a professor of mechanical engineering at the University of the Pacific and a professional engineer in California. He is interested in developing low-cost demonstration devices, especially those related to fluid motion, for informal science education. sshakerin@pacific.edu 